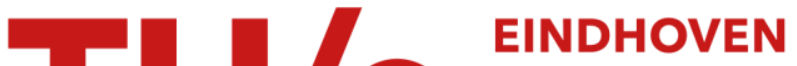

\section{Field dependence of the Néel temperature in pseudo-one- dimensional Heisenberg systems}

\section{Citation for published version (APA):}

De Jonge, W. J. M., Hijmans, J. P. A. M., Boersma, F., Schouten, J. C., \& Kopinga, K. (1978). Field dependence of the Néel temperature in pseudo-one-dimensional Heisenberg systems. Physical Review B, 17(7), 2922-2925. https://doi.org/10.1103/PhysRevB.17.2922

DOI:

10.1103/PhysRevB.17.2922

Document status and date:

Published: 01/01/1978

\section{Document Version:}

Publisher's PDF, also known as Version of Record (includes final page, issue and volume numbers)

\section{Please check the document version of this publication:}

- A submitted manuscript is the version of the article upon submission and before peer-review. There can be important differences between the submitted version and the official published version of record. People interested in the research are advised to contact the author for the final version of the publication, or visit the $\mathrm{DOI}$ to the publisher's website.

- The final author version and the galley proof are versions of the publication after peer review.

- The final published version features the final layout of the paper including the volume, issue and page numbers.

Link to publication

\section{General rights}

Copyright and moral rights for the publications made accessible in the public portal are retained by the authors and/or other copyright owners and it is a condition of accessing publications that users recognise and abide by the legal requirements associated with these rights.

- Users may download and print one copy of any publication from the public portal for the purpose of private study or research.

- You may not further distribute the material or use it for any profit-making activity or commercial gain

- You may freely distribute the URL identifying the publication in the public portal.

If the publication is distributed under the terms of Article 25fa of the Dutch Copyright Act, indicated by the "Taverne" license above, please follow below link for the End User Agreement:

www.tue.nl/taverne

Take down policy

If you believe that this document breaches copyright please contact us at:

openaccess@tue.nl

providing details and we will investigate your claim. 


\title{
Field dependence of the Néel temperature in pseudo-one-dimensional Heisenberg systems
}

\author{
W. J. M. de Jonge, J. P. A. M. Hijmans, F. Boersma, J. C. Schouten, and K. Kopinga \\ Department of Physics, Eindhoven University of Technologv, Eindhoven. The Netherlands
}

(Received 19 September 1977)

\begin{abstract}
The field dependence of $T_{N}$ has been measured in a series of pseudo-one-dimensional Heisenberg systems with a varying degree of one dimensionality for magnetic fields up to $90 \mathrm{kOe}$. In all cases an anomalous increase of $T_{N}$ was found. The results are compared with detailed numerical calculations on the basis of the isotropic classical Heisenberg model.
\end{abstract}

\section{INTRODUCTION}

According to recent reports, both experimental and theoretical, the Néel temperature of several systems may increase drastically when an external magnetic field is applied. So far, the scarce evidence seems to indicate that this anomalous behavior is restricted to pseudo-low-dimensional antiferromagnetic Heisenberg or $X Y$ systems. Experimental results were reported on $\mathrm{CsNiCl}_{3}$, tetramethylammonium-manganesetrichloride (TMMC), ${ }^{2} \mathrm{CsMnCl}_{3} \cdot 2 \mathrm{H}_{2} \mathrm{O},{ }^{3}$ and $\alpha-\mathrm{Cu}-\mathrm{N}$ Sal $[\alpha$-bis $(\mathrm{N}$-methylsalicylaldiminato $)-\mathrm{Cu}] .^{4}$ The theoretical behavior of a system of loosely coupled Heisenberg chains was studied by Imry et al. ${ }^{5}$ From the suppression of the quantum fluctuations in a field they deduced a small increase of the ordering temperature $T_{N}$. The classical $(S=\infty)$ Heisenberg chain in an applied field has been studied by Blume et al. ${ }^{6}$ and by Lovesey and Loveluck. ${ }^{7}$ They obtained the two-spin transverse correlation functions, the wavevector-dependent susceptibility, and the correlation length. Subsequently Villain and Loveluck ${ }^{8}$ argued that from the relation between $T_{N}$ of a system of weakly coupled chains and the correlation length of the individual chains, the increase of $T_{N}$ for $H$ perpendicular to the preferred direction may be qualitatively understood.

In this paper we will present data on the field dependence of $T_{N}$ for a series of selected pseudoone-dimensional Heisenberg systems in high fields. Moreover, we will confront these data with quantitative theoretical results calculated on the basis of the $S=\infty$ Heisenberg model and show that this model explains to a large extent (at least for $S=\frac{5}{2}$ compounds) the experimental results.

\section{EXPERIMENTAL}

The majority of the experimental data was obtained by a continuous heating method. The single crystals were mounted on a thin copper plate together with a heater and a set of thermometers. This assembly was adiabatically suspended in a superconducting solenoid. The Néel temperature was identified by the maximum of the specific-heat anomaly, monitored by a change in the time derivative of the temperature at a constant heat input. At low fields some data points were obtained by a nuclear magnetic-resonance technique in a way similar to that applied by Dupas et al. ${ }^{2}$ The systematic error in $T_{N}$, due to uncertainties in the calibration of the field dependence of the thermometer, did amount to a maximum of $30 \mathrm{mK}$ at high magnetic fields. The experimental resolution was of the order of $3 \mathrm{mK}$ at $H=0$, gradually changing to $10 \mathrm{mK}$ at $H=90 \mathrm{kOe}$.

The experiments were performed on the $S=\frac{5}{2}$ compounds $\mathrm{CsMnCl}_{3} \cdot 2 \mathrm{H}_{2} \mathrm{O}(\mathrm{CMC}), \mathrm{CsMnBr}_{3} \cdot 2 \mathrm{H}_{2} \mathrm{O}$ (CMB), $\left(\mathrm{CH}_{3}\right)_{4} \mathrm{NMnCl}_{3}$ (TMMC), and $\left(\mathrm{CH}_{3}\right)_{2} \mathrm{NH}_{2} \mathrm{MnCl}_{3}$ (DMMC), and on the $S=\frac{1}{2}$ compound $\mathrm{CuCl}_{2}$ dipyridine (CuPC). Some of the relevant characteristic parameters are summarized in Table I. From this table it may be seen that we have chosen a series in which the degree of one dimensionality varies over a relatively large range. The entries of the table [the ratio of the interchain coupling $J '$ and the intrachain coupling $J$, the critical entropy $S_{\text {crit }}$, and $\left.k T_{N}(0) / 2 J S(S+1)\right]$ are various entities by which the spatial magnetic dimensionality of the systems can be estimated. Since we are interested in the phase boundary with $H$ perpendicular to the moments it is of importance to know the zero-field array of the magnetic moments in the ordered state. For the whole series, except maybe for CuPC, one may safely assume the anisotropy to be mainly of dipolar origin. In antiferromagnetic chain-like compounds this will favor a direction perpendicular to the chain. Explicit data are only available for CMC and CMB, ${ }^{9.10}$ in which cases the preferred axis and intermediate axis are indeed in a plane perpendicular to the chain. The in-plane anisotropy amounts to 500 and $800 \mathrm{Oe}$, respectively. Both DMMC and TMMC have a chainlike structure of face-shared $\mathrm{MnCl}_{6}$ octahedra. Data on the ordered state of DMMC have been obtained recently in our laboratory. "Apart from the values for 
TABLE I. Review of some characteristic magnetic parameters of the compounds studied in this paper. The definitions of the various entities are given in the text.

\begin{tabular}{ccccccr}
\hline \hline Compound & $T_{N}(0)$ & $S_{\text {cril }}(\%)$ & $\frac{J}{k}$ & $\frac{J^{\prime}}{J}$ & $\frac{k T_{N}(0)}{2 J S(S+1)}$ & Ref. \\
\hline $\mathrm{CsMnBr}_{3} \cdot 2 \mathrm{H}_{2} \mathrm{O}$ & 5.75 & 15 & -2.6 & $10^{-2}$ & $12.6 \times 10^{-2}$ & 10 \\
$\mathrm{CsMnCl}_{3} \cdot 2 \mathrm{H}_{2} \mathrm{O}$ & 4.88 & 12 & -3.0 & $8 \times 10^{-3}$ & $9.3 \times 10^{-2}$ & 9 \\
$\left(\mathrm{CH}_{3}\right)_{2} \mathrm{NH}_{2} \mathrm{MnCl}_{3}$ & 3.60 & 3 & -5.8 & $10^{-3}$ & $3.6 \times 10^{-2}$ & 11 \\
$\left(\mathrm{CH}_{3}\right)_{4} \mathrm{NMnCl}_{3}$ & 0.85 & 1 & -6.7 & $10^{-4}$ & $0.7 \times 10^{-2}$ & 12 \\
$\mathrm{CuCl}_{2} \cdot 2 \mathrm{NC}_{5} \mathrm{H}_{5}$ & 1.14 & 3 & -13.4 & $3 \times 10^{-4}$ & $5.6 \times 10^{-2}$ & 13 \\
\hline \hline
\end{tabular}

$T_{N}, S_{\text {crit }}, J$, and $J^{\prime}$ given in Table I, it could be concluded that also in this case the preferred direction is perpendicular to the chain and the in-plane anisotropy amounts to $\sim 250 \mathrm{Oe}$. For TMMC the ordered state is less clear. ${ }^{12}$ The situation is somewhat complicated by a phase transition which creates crystallographic domains with a pseudohexagonal symmetry which obscure the anisotropy perpendicular to the chains. Nevertheless, TMMC is the best high-spin approxima-

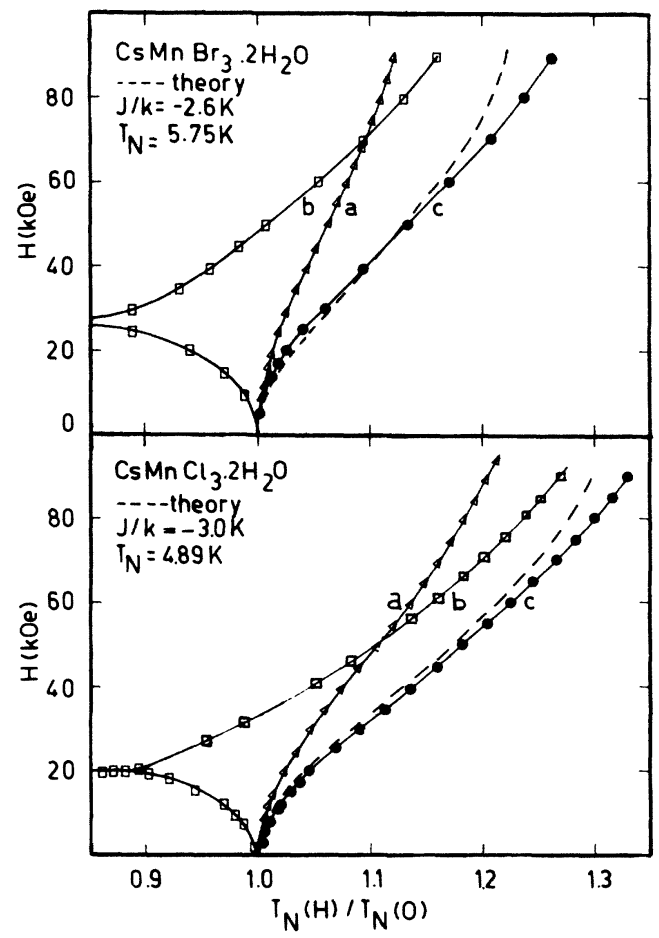

FIG. 1. Phase diagram of $\mathrm{CsMnBr} 3 \cdot 2 \mathrm{H}_{2} \mathrm{O}$ and $\mathrm{CsMnCl}_{3} \cdot 2 \mathrm{H}_{2} \mathrm{O}$. For small fields the phase transition along the $\vec{a}$ and $\vec{c}$ axis can be described by $T_{N}(H) / T_{N}(0)=1+a H^{2}$. For CMB the value of $a$ amounts to $3.3 \times 10^{-5} \mathrm{kOe}^{-2}$ for $\vec{H} \| \vec{a}$ and $6.0 \times 10^{-5} \mathrm{kOe}^{-2}$ for $\vec{H} \| \vec{c}$. For CMC the corresponding values of $a$ are $6.5 \times 10^{-5}$ and $12.5 \times 10^{-5}$ $\mathrm{kOe}^{-2}$. The dashed curve represents the theoretical estimate based on the parameters given in Table $\mathrm{I}$. tion to a one-dimensional system available at the moment and is therefore included in the comparison. The $S=\frac{1}{2}$ system CuPC (Ref. 13) has been measured because one should expect a much more quantummechanical behavior.

\section{RESULTS AND DISCUSSION}

The data on the phase diagrams are shown in Figs. 1 and 2, except for CuPC and TMMC, which will be shown only in reduced form in Fig. 4(b). The measurements have been performed along all relevant axes, except for TMMC, where no phase transition could be detected along the chain direction. The increase of $T_{N}$ as a function of applied field is obvious in all compounds, even for the transition between the spin-flop and paramagnetic state in CMC, CMB, and DMMC. From inspection of Figs. 1 and 2 it is also

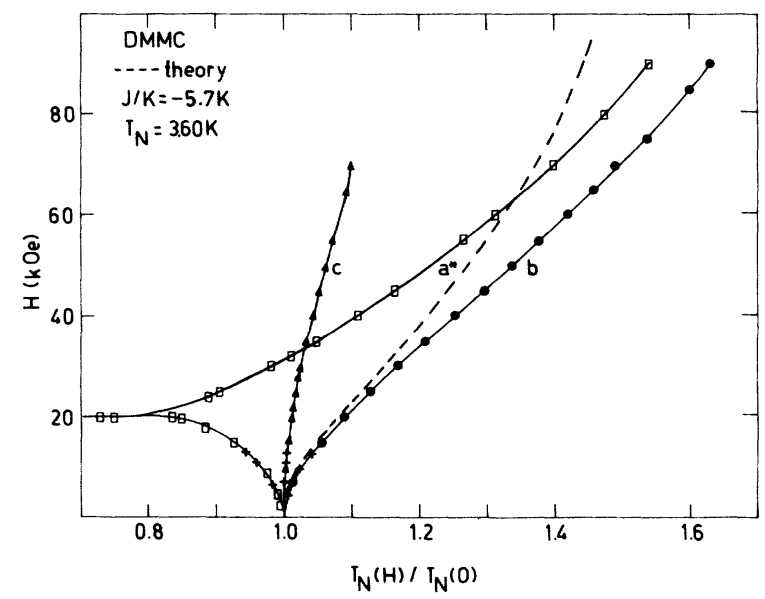

FIG. 2. Phase diagram of $\left(\mathrm{CH}_{3}\right)_{2} \mathrm{NH}_{2} \mathrm{MnCl}_{3}$. The data at low fields are obtained by nuclear magnetic resonance. For small fields the phase transition along the $\vec{b}$ and $\vec{c}$ axis can be described by $T_{N}(H) / T_{N}(0)=1+a H^{2}$. The value of $a$ amounts to $2.3 \times 10^{-4}$ for $\vec{H} \| \vec{b}$ and $3.3 \times 10^{-5}$ for $\vec{H} \| \vec{c}$. The dashed curve represents the theoretical estimate based on the parameters given in Table $\mathbf{I}$. 
clear that the anisotropy has a drastic influence in $\mathrm{CMC}, \mathrm{CMB}$, and DMMC. It is interesting to note that in all three compounds the maximum effect is observed with $H$ parallel to the intermediate anisotropy axis. In TMMC no anisotropy could be detected, probably due to the pseudohexagonal symmetry. In $\mathrm{CuPC}$ anisotropy between the three crystallographic directions was rather small and only the average is plotted in Fig. 4(b).

Insertion of the appropriate values for each compound in the formula for $T_{N}(H) / T_{N}(0)$ derived by Imry et al. ${ }^{8}$ yields values which are one order of magnitude too small. This fact agrees with an earlier observation by Dupas et al. ${ }^{2}$ Up till now no quantitative results were available from the classical spin approach, quoted in the Introduction, apart from the suggested limit ${ }^{8} T_{N}(H) / T_{N}(0)=\sqrt{2}$. Since we have chosen to investigate mainly $S=\frac{5}{2}$ systems we might expect this theory to be applicable.

The calculations have been performed following Blume et al. ${ }^{6}$ and Lovesey and Loveluck. ${ }^{7}$ Basically they involve the computation of the staggered susceptibility by the transfer-matrix technique for the isolated Heisenberg chain. A set of characteristic results is shown in Fig. 3.

In the molecular-field approach one may now derive that for a system of loosely coupled chains, the Néel temperature is implicitly given by ${ }^{14}$

$$
2 z J^{\prime} \chi\left(T_{N}\right)=1
$$

where $\chi$ is the staggered susceptibility of an isolated chain and $z J^{\prime}$ is the interchain interaction. Application of this relation results in the field dependence of $T_{N}$.

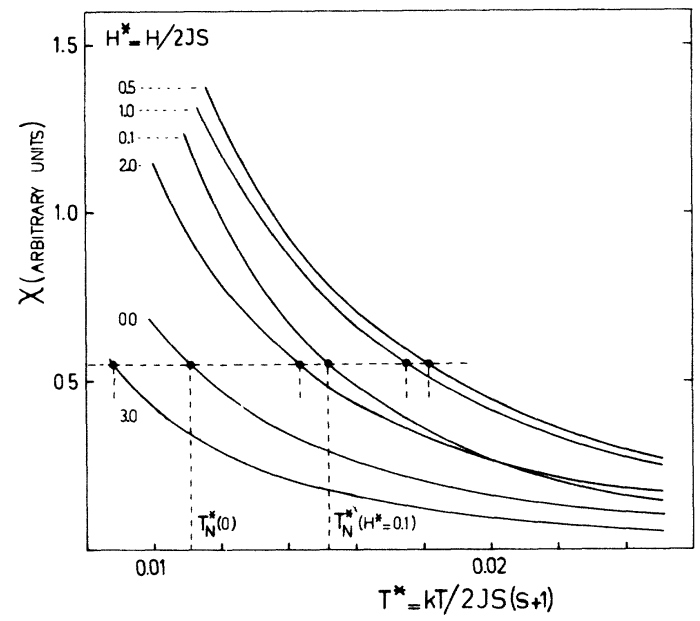

FIG. 3. Typical examples of numerical estimates for the staggered susceptibility of an isolated classical Heisenberg chain as a function of reduced field and temperature. The construction to obtain $T_{N}(H)$ by adopting Eq. (1) is also shown.
Figure 3 illustrates the graphical method used to obtain $T_{N}(H)$. In order to avoid the intrinsic inaccuracy brought about by the molecular-field approach, temperatures were scaled to the zero-field ordering temperature $T_{N}(0)$. Some typcial results are shown in Fig. 4(a). The parameter $k T_{N}(0) / 2 J S(S+1)$ indicates the degree of one dimensionality.

Alternatively, one may insert a simplified relation between $\chi$ and the correlation length $\xi$ in (1), and obtain a simple proportionality between $T_{N}$ and $\xi .^{5.6}$

Such a relation can be particularly useful when only a numerical or analytical estimate of $\xi$ is available. Application of such a relation in this case yields results which are qualitatively similar to these shown in Fig. 4 (a), but give rise to a somewhat smaller field effect on $T_{N}(H) / T_{N}(0)$.

From the appropriate values for $J$ and $T_{N}(0)$ for each compound we calculated $T_{N}(H)$ with (1). The results are plotted in Figs. 1 and 2 together with the

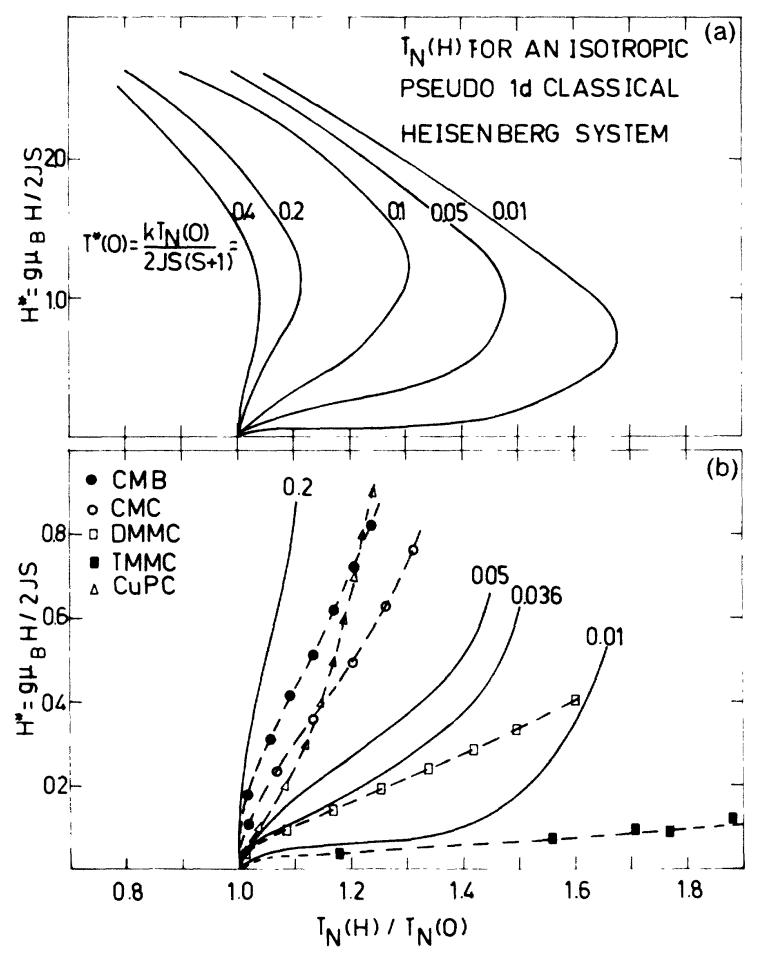

FIG. 4. (a) Numerical estimates for $T_{N}(H) / T_{N}(0)$ for a system of loosely coupled classical Heisenberg chains for several values of "dimensionality" parameter $k T_{N}(0) / 2 J S(S+1)$. (b) Experimental magnetic phase diagrams on a reduced field and temperature scale. For CMC, $\mathrm{CMB}$, and DMMC only the data points obtained for the field direction showing the largest effect are shown. For CuPC only the average is shown. The data for TMMC is supplemented with recent measurements by Groen et al. (Ref. 2). For comparison some theoretical estimates for varying $k T_{N}(0) / 2 J S(S+1)$ are also shown. 
experimental results.

Bearing in mind that the theory does not include the anisotropy, inspection of the results for the individual compounds show that the effect of an external field on the susceptibility may very well form the major contribution to the field dependence of $T_{N}$. For small values of $J^{\prime} / J$ [or $k T_{N}(0) / 2 J S(S+1)$ ] the agreement seems to get worse. However, one should note that in the present calculations we have not included any adjustable parameters, whereas small changes in the parameter $k T_{N}(0) / 2 J S(S+1)$ may have a rather drastic effect. In Fig. 4(b) the experimental results (only for the field direction in which the largest effect was observed) are plotted on a reduced scale together with some theoretical curves. From this figure it may be seen that a decrease of the experimental value of $k T_{N}(0) / 2 J S(S+1)$ leads to an increase of $T_{N}(H) / T_{N}(0)$, in agreement with the theoretical prediction. Moreover, the characteristic shape of the experimental curves matches reasonably well the theoretical curves for CMC and CMB, whereas CuPC behaves quite differently in the same region of $T_{N}(H) / T_{N}(0)$, probably due to quantum effects which are not included in the present theory. For lower values of the "dimensionality" parameter $k T_{N}(0) / 2 J S(S+1)$ (notably DMMC and TMMC) the experimental data for $T_{N}(H) / T_{N}(0)$ systematically exceeds the theoretical predictions, especially for higher fields. Qualitatively this may be understood from the additional increase of $T_{N}(H) / T_{N}(0)$ arising from the suppression of quantum fluctuations in fields. As already suggested by Imry et $a l^{8}$ this effect increases for smaller values of $J^{\prime} / J$.

In view of the results of this first systematic exploration of the field dependence of $T_{N}$ in pseudoone-dimensional Heisenberg systems, we are tempted to conclude that the experimental behavior of $T_{N}(H)$ can be fairly well described by the effect of the magnetic field on the susceptibility of the individual chains, at least for high-spin compounds. It will be necessary, however, to extend the theory with uniaxial or orthorhombic anisotropy, since it appears that small anisotropies may have a large influence. Preliminary attempts have already indicated that for CMC the reported values for the anisotropy reproduce the experimental results along the $a$ and $c$ axis rather well. Moreover, an extension beyond the classical model seems necessary to account for the quantum effects.

\section{ACKNOWLEDGMENTS}

The authors wish to acknowledge the assistance of J. Millenaar and J. A. M. Roos. This research is partially supported by the Stichting Fundamenteel Onderzoek der Materie.
'D. P. Almond and J. A. Rayne, Phys. Letl A 55, 137 (1975).

${ }^{2}$ C. Dupas and J.-P. Renard, Solid State Commun. 20, 381

(1976); J. P. Groen, T. O. Klaassen, and N. J. Poulis, Phys. Letl A 62, 453 (1977).

${ }^{3}$ G. J. Butterworth and J. A. Woollam, Phys. Lett. A $\underline{29}, 259$ (1969).

${ }^{4}$ W. G. Clark, L. J. Azevedo, and E. O. McLean, in Proceedings of the Fourteenth International Conference on Low Temperature Physics, Otaniemi, Finland, edited by M. Krusius and M. Vuorio (North-Holland, Amsterdam, 1975), p. 391.

${ }^{5}$ Y. Imry, P. Pincus, and D. Scalapino, Phys. Rev. B $\underline{12}, 1978$ (1975).

${ }^{6} \mathrm{M}$. Blume, P. Heller, and N. A. Lurie, Phys. Rev. B 11 , 4483 (1975)

${ }^{7}$ S. W. Lovesey and J. M. Loveluck, J. Phys. C 9,3639 (1976).

8J. Villain and J. M. Loveluck, J. Phys. (Paris) Lett. 38, L77 (1977).

${ }^{9}$ R. D. Spence, W. J. M. de Jonge, and K. V. S. Rama Rao, J.
Chem. Phys. 51, 4694 (1969); K. Kopinga, T. de Neef, and W. J. M. de Jonge, Phys. Rev. B 11, 2364 (1975); T. Smith and S. A. Friedberg, Phys. Rev. 176, 660 (1968).

${ }^{10}$ C. H. W. Swüste, W. J. M. de Jonge, and J. G. A. M. van Meijel, Physica (Utr.) 76, 21 (1974); K. Kopinga, Phys. Rev. B 16, 427 (1977).

"1R. D. Caputo and R. D. Willett, Phys. Rev. B 13, 3956 (1976); K. Takeda, J. C. Schouten, K. Kopinga, and W. J. M. de Jonge, Phys. Rev. B 17, 1285 (1978).

${ }^{12}$ R. Dingle, M. E. Lines, and S. L. Holt, Phys. Rev. 187, 643 (1969); R. J. Birgeneau, R. Dingle, M. T. Hutchings, G. Shirane, and S. L. Holt, Phys. Rev. Lett. 26, 718 (1971); W. J. M. de Jonge, C. H. W. Swüste, K. Kopinga, and K. Takeda, Phys. Rev. B $\underline{12}, 5858$ (1975); P. S. Peercy, B. Morosin, and G. A. Samara, ibid. 요, 3378 (1973).

${ }^{13}$ K. Takeda, Y. Yamamoto, and T. Haseda, Phys. Lell. A 45 , 419 (1973); Y Endoh, G. Shirane, R. J. Birgeneau, P. M. Richards, and S. L. Holt, Phys. Rev. Lett. 32, 170 (1974). ${ }^{14}$ See, for instance, Y. Imry, Phys. Rev. B $\underline{13}, 3018$ (1976), and references therein. 